\title{
Study about the Goal and Key Tasks for the 13th Five-year Transportation Development Planning
}

\author{
Zhang Wenru \\ Weifang University of Science and Technology, Shouguang,Shandong , 262700, China \\ 25132928@qq.com
}

Keywords: Research object. Task.Expected results

\begin{abstract}
The paper clears the transportation development direction and the key construction field of the 13th five-year planning, establishs the evaluation system of the main mode of transport capacity in various fields and the evaluation system around "the four transport objectives" , puts forward key measures and practical policy recommendations.
\end{abstract}

\section{The Goal of the Research}

The goal of the task is to set the guiding ideology, the direction, demand and the objective of the development, key areas or project, the investment and financing system, assurance measures for the outline of the transportation development and plan of the 13th five-year plan to be hold, it's based on that, the current situation and problem of the transportation development in the 12th five-year plan, the judge of situation of the 13th transportation development to be faced, it can sustain organizing the national 13th five-year transportation development planning, guarantee the transportation developing efficiently and healthy, advance the system establishment of the comprehensive transportation.

Formulate the 13th Five-year Planning Guiding Ideology. On the basis of the 12th five-year transportation development planning and guiding ideology and on the background of the major national strategy and policy to guide the 13th five-year transportation development direction, development target, research content and key areas as the purpose. Through the analysis of the national long-term development goal, according to principles of forward looking into the future, keeping pace with the times, seeking truth from facts, and appropriate advance, combined with the future development of the understanding of the transportation demand to study and formulate the 13th five-year transportation development planning guiding ideology which can adapt to the national strategic policy, to meet the demand of traffic and transportation development. It has a high generalization, overall coordination, social adaptability and development guidance, to ensure that transportation comprehensive sustainable development, provide a guideline for planning and security plan formulation.

Clear the Transportation Development Direction of the 13th Five-year Planning.Combining with the transformation factor of economic development mode, industrial layout and opening to the outside world, around the four traffic goal, outstanding low carbon, financing and other keys, on the basic of the significant problem which made in the 13th five-year transportation development outline strategy and achieving the effect, clear in what way and what kind of concrete method to ensure the implementation, clear transportation development direction during the 13th five-year .

Comb the Transport Development Demand Distribution and Characteristics of the 13th Five-year Planning.This task aims to analysis our country transportation development demand during the 13th five-year, multi-faceted and full view positioning transportation development needs from infrastructure, transportation equipment, transportation services, technology and information, green and low carbon transportation, emergency safety aspects. In addition, summarizing all the demand of the time trend, spatial distribution characteristics, the change of structure characteristics, the relationship between supply and demand feature and analyzing these characteristics, to construct the convenient, safety, economic, and efficient transportation system and contribute to building a resource-saving and environment-friendly society. 
The Objective of the 13th Five-year Transportation Development Planning.According to the basic policy of the transportation development stage state, considering the outstanding results of the 12th five year plan, combined with the development environment and needs to grasp the whole set the overall development objectives of the 13th five-year transportation planning. Formulate the specific target according to the infrastructure, transport equipment, transport services, technology and information, green and low carbon transportation, safety emergency, investment and financing mechanisms and other aspects and according to the development direction of the concrete field. Develop phased goals according to the development speed and difference in the every area of the transportation.

Plan Key Construction Field (or Project).Comb the completion of the key transportation construction field during the 12th Five Year development planning and continue to do the unfinished things. On the other hand, with international vision and open thinking, contrast the development difference of domestic and foreign transportation aspects breadthwise, on the implementation of new urbanization national strategy, integration of different modes of transport network, mining and constructing an important hub, constructing the corresponding traffic integration of intelligent transport system network. Basing on the relevant state policies and the development of transport demand, through summary and analysis to determine the long-term construction areas and key construction areas during the 13th five-year transportation development planning and provide theoretical and practical basis.

To Promote the Reform of Budget, Investment and Investment and Financing System.On the basis of deep research on successful cases at domestic and overseas, the essential is to summarize the characteristics of investment and financing mechanism and system of transportation investment demand in transportation industry.Through the reference of the successful case from the foreign country and the analysis of various budget and financing program, budget and financing plan which suits the development of the current comprehensive traffic in our country has been proposed,and the specific implementation measures and channels has been gived.Based on the existing investment and future development,the points are formulating subsidies in the field of the transportation infrastructure construction and public transport subsidy, research transportation finance system, adjusting the transportation investment and financing work ideas, and discussing the development policy, striving for more fiscal funds into the transportation enterprise actively and governing the other social capital better in accordance with the "government-led, hierarchic responsible, diverse financing" the basic principles. The measure is to explore the capital combination between government and socity,the financing development model of the combination between traffic infrastructure construction and land comprehensive development,and to build diversified capital structure of the transportation infrastructure investment and financing channels and new pattern, etc.

The Establishment of " The 13th Five-year Planning " Evaluation Index System.Considering the completion of the 12th five-year planning and new features of "The 13th five-year planning", the new stage should update "The 13th five-year planning" evaluation index and establish "The 13th five-year" transportation planning evaluation index system based on the four angles of "comprehensive transportation, intelligence transportation, green transportation and safe transportation", the evaluation index system mainly involves constructive indicators, instructive indicators and service indicators. With emphasis on the evaluation of the effect of transportation capacity, the service level of transportation, low-carbon and energy-saving and emission-reduction, we establish the evaluation system of the main mode of transport capacity in various fields and the evaluation system around "the four transport objectives" by adopting the method of comprehensive evaluation.

Extract the Main Measures and Policy.Aim at the insufficient aspect during 12th five-year and the future development direction,the purpose is to put forward key measures and practical policy recommendations which focus on institutional guarantee, financing policy, science and technology innovation the guarantee, legal guarantee, personnel security and the construction of spiritual civilization of security. The measure is to strengthen the organization leadership,strengthen the 
guidance of planning,promote the guarantee of system and machining;to strengthen the financial guarantee,improve the investment and financing policies, strengthen the investment and financing policy support; to strengthen the construction of the legal system, deepen the reform of institutional mechanisms, improve the guarantee of laws, strengthen the construction of talents, provide personnel and intellectual support, pay attention to the intellectual protection;to strengthen the construction of spiritual civilization, promote industry development of soft power, strengthen the protection of the construction of spiritual civilization; to establish scientific outlook on development, enhance the innovation ability of science and technology innovation, consolidate the guarantee of technological innovation.

\section{Key Work Direction}

The outline of 13th five-year transportation development planning should forcus on non traditional innovation transportation development,non traditional innovative transportation development including (but not limited to):

The Development of Comprehensive Transportation.Comprehensive transportation is the product of the market economy which develops to a certain stage. In the science and technology innovation and system innovation effect, a modern transportation generated form of organization is produced. It synthesized various transportation modes as a organic whole system,and conduct systematic study,systematic planning and systenmatic construction on this whole. The purpose is to provide more safety, quick, convenient, comfortable, economical and quality service for human economic development, social progress and the passenger and freight transport .

At present, our country still lack of a comprehensive transportation stategy of national development. Due to the lack of strategy, transportation planning is short of unity and coordination. In transportation infrastructure construction, the repeat construction phenomenon emerges; in the operation of transportation industry, there emerges low efficiency as a result of the lack of cooperation and cohesion among various modes of transport, the city traffic and inter city traffic, which influence the development of country's overall competitiveness.

The formulation of 13th five-year transportation development planning outline should be judged from a strategic height, global perspective, the comprehensive transportation development problem of our country need be identificed, In the light of the hundred or more history on the aspects of economic and social development from developed countries, and the China's experience from accumulated 30 years of reform and openness, complex relationship among the development comprehensive transportation has been planned as a whole. Considering the effective bind between the recent behavior and long-term strategy traffic development, and realizing the theory innovation of comprehensive transportation development, exploring the mode of coordinated transportation development among different regions in our country, strengthening the comprehensive traffic of transportation sustainable development ability in our country continuously, the policy-making reference for the preparation of "13th five-year" transportation development planning has been provided .

The Various Ways of Energy Saving and Carbon Reduction of the Passenger and Cargos Transportation.Transportation is one of the main industries of fossil energy consumption and carbon dioxide or other gases pollution emissions in China. As a pillar industry for economic development, from the view of social economy development process of developed countries, transportation industry will be the fastest growing energy consumption industry in the future, therefore, the potential and the pressure of carbon dioxide emission reduction of the transportation are bigger than other industries. In order to accommodate the self-development and the requirements of environmental protection, in the 13th five-year transportation development planning ,it is necessarily continue to emphasize on the energy conversation and mission reduction, to determinate the goals and to make the strategic planning and policy measures. At the same time, from the view of the economic development and environmental protection point, the analysis of the differences of the transportation development 
between the regions, will be lead to a more detailed division of the task of the energy-saving emission reduction so that to implement the Chinese transportation overall energy saving and emission reduction target effectively.

Financing Mode (Include Private Investment). The construction of transportation projects are often with the characteristic of large investment and long return cycle, so it is need a high requirement of investors, who have lots of capital investment and strong ability to bear the risk. With the gradual open market in the field of transportation investment in our country, private capital are allowed to investment into more and more fields, the government is also actively encourage the private capital put into the infrastructure, so the diversification of the main investors and the diversification of the financing channels of the transportation industry is the inexorable trend, and it is also the main point of the exploration in the transportation industry investment and financing mode .

In addition, the accumulated debt of the transportation industry over the years in China which has been lead difficult to continue load funding for the construction, so it is require to built a diversified capital structure of transportation infrastructure, such as: equity financing; and to make a reference of the useful experience of international infrastructure development, to explore the combination of government and social capital financing development mode, such as: the company partner PPP mode; and to explore the combination of transportation facilities construction and land comprehensive development mode etc.. In PPP mode, the infrastructure of transportation, the planning, design construction, enterprises of transportation can mobilize their own resources to participate into the development and construction, and strive to obtain the rights, interests and benefits of their own enterprises in the development of the transportation.

\section{The Expected Results}

(1)Through the comparative study of the guiding ideology of three five-year transportation plan, to summarize the emphasized guiding ideology, the main method and the task since 2000. combine the task one and grasp the accomplishment of the 12th five-year transportation planning, and on the base that to determine the guiding ideology of 13th five-year transportation planning.

(2)To determination of the prioritize objects of the transportation structure adjustment, the informatization and the intellectualization, the environmental protection, the energy-saving emission reduction, the safety emergency security, the comprehensive transportation and other aspects, combine with the actual situation in each field, to refine the 13th five-year transportation development direction.

(3)Make classification of the demands of the comprehensive transportation development, combine with the characteristics of 13th five-year special development period, grasp the big strategic planning background of the national new urbanization planning and the silk road " one belt and one road ", summarize the development need of each transportation field with the characteristics in time trend, spatial distribution, structure change and the relationship between supply and demand etc..

(4)On the basis of the 12th five-year transportation development planning, combine with factors of the significant national policy, development strategy, industry dynamic state, institutional reformation etc. impact on the transportation demand and supply, using the method of system science, from the aspects of the direction target, the basic construction target, the management system target, the service target, the constructive target etc. put forward 13th five-year transportation development specific goals, and as a basis for making the general goal. Using appropriate advancing principles, to assign the specific objects of the transportation development into the five-year planning period, obtain the development goals in stages.

(5)Summarize the foreign experiences in transportation planning, development trend and characteristics, take its essence, and discard its dross, to know the need, challenge and the latest development of the transportation field in our country, combine with our special national conditions, carding 13th five-year planning of comprehensive transportation key construction areas and projects. 
(6)On the basis of comparing and analyzing different budget and financing scheme, put forward the suitable budget and financing way for Chinese current different transportation methods development and give the specific implementation measures and channels.

(7)Make the establishment of five main modes of transport (railway, highway, waterway, aviation, postal) to establish the evaluation system of transport capacity, the qualitative and quantitative analysis on effect of "four traffic" to the 13th five-year transportation planning.

(8)From aspects of the mechanism and system of security, investment and financing security, science and technology innovation security, laws and regulations security, talent team and intelligence security, spiritual civilization construction security etc. to put forward to related measures and policies to ensure the smooth implementation of the 13th five-year planning.

\section{References}

[1]Cambridge Systematics,Inc..Long-Term Availability of Multimodal corridor Capacity[R].England:Res.Agency, 1996.

[2] VlamdimirMarianov.Daniel Serra. Location of Hubs in a Competitive Environment [J].European Journal of Operational Research, 1999:367-371

[3]Snehalnay Khasnabis.Land Use \& Transit Integration and Transit Use Incentives [J].Transportation Research Board, Washington,DC.2001

[4] Maria da Graca Costa,Maria Eugenia Capivo,Joao Climaco.Capacitated single allocation hub location problem-A bi-criteria approach [J].Computers \& Operations Research, November 2008,35(11):3671-3695

[5] Marcos Roberto Silva,Claudio B.Cunha. New simple and efficientheuristics for the uncapacitated single allocation hub location problem [J]. Computers \& Operations Research, December 2009, 36(12):3152-3165

[6] Natashia Boland,Mohan Krishnamoorthy,Andreas T.Ernst,et al. Preprocessing and cutting for multiple allocation hub location problems [J]. European Journal of Operational Research, 16 June 2004, 155(3):638-653

[7]Parsons-clough Harbor.Existing corridor conditions and opportunities-I-87 multimodal corridor study[R].New York: New York State Department of Transportation, 2004.

[8]Reid Croether\&Partners Ltd..Multimodal corridor transportation study-horseshoe bay to highway 97[R].New York: Ministry of Transportation\& highway, 2001.

[9]Yeates.Main Street: Windsor to Quebec City [M].Ottawa: The Macmillan Company of Cannada Limited, 1975.

[10]Jifeng $\mathrm{Wu}$, Gang-len Chang.An integrated optimal control and algorithm for commuting corridors [J].International Transportations in Operational Research, 1999, 6(1):39-55.

[11]Markos Papageorgiou.An integrated control approach for traffic corridors [J].Transportation Research C, 1995, 3(1):19-30.

[12]Cristina Diakaki,Markos Papageorgiou,Tom Mclean.Simulation studies of integrated corridor control in Glasgow[J].Transportation Research C,1997,5(3/4):211-224.

[13]Van Henggel.Citizens near the path of least resistance: travel behavior of century Freeway corridors residents [D].University of California, Ph.D, 1996.

[14]Osuji, lifford Ihejirika.Impact of anticipated transportation improvement on land values in Chicago [D].University of Illinois at Chicago, Ph.D, 1994. 
[15]E.R.Petersen.A highway corridor planning model: QROAD [J].Transportation Research Part A.2002, 36(2):107-125. 